\title{
Haemolysin produced by Vibrio cholerae non-01 is not enterotoxic
}

\author{
D. V. SINGH, B. N. SHUKLA and S. C. SANYAL* \\ Department of Microbiology, Institute of Medical Sciences, Banaras Hindu University, Varanasi 221 005, India
}

\begin{abstract}
Of 28 isolates of Vibrio cholerae non-01 (10 from diarrhoeal patients and 18 from environmental sources) examined for haemolytic activity and its correlation, if any, with enterotoxic activity, 24 showed haemolysis. The four non-haemolytic isolates showed haemolysis after consecutive passages through rabbit ileal loops (RILs). The titres of haemolytic activity were 4-64 HU/ml irrespective of their source. Eight $(28.5 \%)$ of the non-O1 isolates caused fluid accumulation; six (25\%) were haemolytic and two (50\%) non-haemolytic. The remaining isolates showed enterotoxic activity after one-to-three consecutive passages through RILs irrespective of their haemolytic character and source. Environmental isolates caused significantly more fluid accumulation than the diarrhoeal isolates. All these isolates reverted to their original non-toxigenic character on repeated subculture or on storage in the laboratory, but continued to show haemolytic activity. The results of the present study indicate that $V$. cholerae non-O1 strains are potentially enterotoxigenic independent of their haemolytic character and source, and enterotoxin, not haemolysin, is the factor most likely to be responsible for their enterotoxic activity.
\end{abstract}

\section{Introduction}

Vibrio cholerae non-O1 strains have been implicated in sporadic and localised outbreaks of cholera-like diarrhoea $[1,2]$, which is sometimes accompanied by fever, and blood and mucus in the stool. Apart from their diarrhoeagenic potential, these organisms have also been implicated in a few cases of extra-intestinal infections, such as wound infection, septicaemia and cellulitis [3-5]. A large number of $V$. cholerae non-O1 strains produce cholera-like toxins, although some strains do not $[2,6]$. In addition to cholera toxin (CT), several other extracellular products such as the new cholera toxin [7], heat stable enterotoxin (NAGST), a thermostable direct haemolysin, shiga-like toxin and haemagglutinin have been reported to play a role in the disease process [8-14]. More recent reports suggest that the haemolysin produced by $V$. cholerae non-Ol is identical to $V$. cholerae biotype El Tor haemolysin $[15,16]$. It has also been suggested that the El Tor-like haemolysin of $V$. cholerae non-O1 can cause fluid accumulation mixed with mucous and blood in rabbit ileal loops (RIL) [17]. Alm et al. [18] indicated that the haemolysin may be enterotoxigenic because fluid accumulation in RILs was not observed when the whole determinant was deleted from the chromosome of a CT gene-negative but diarrhoea-

Received 1 Aug. 1995; accepted 17 Nov. 1995

${ }^{*}$ Corresponding author: Professor S. C. Sanyal. producing strain of El Tor biotype. However, earlier observations made in this laboratory indicate that $\mathrm{El}$ Tor-like haemolysin is not responsible for fluid outpouring in RILs because non-haemolytic strains of $V$. cholerae biotype El Tor caused fluid accumulation [19]. These reports caused confusion about the nature of the enterotoxin in $V$. cholerae non-O1. Therefore, 28 diarrhoeal and environmental isolates of $V$. cholerae non-O1 were examined for haemolytic and enterotoxic activities, with particular interest in any change in enterotoxicity after passage through RILs and any correlation with haemolytic activity.

\section{Materials and methods}

\section{Bacterial strains}

Twenty-eight strains of $V$. cholerae non-O1 isolated from diarrhoeal stools (10) and from environmental sources, such as the River Ganga (15) and sewage (3) were included in the study. The strains were identified by the method recommended by WHO [20]. The strains were maintained in peptone agar stab cultures at room temperature and did not undergo more than three subcultures before the experiments.

\section{Detection of haemolysis}

Preliminary testing for haemolysis by $V$. cholerae nonO1 strains was performed by inoculating 4-5-h growths of each organism in Brain Heart Infusion Broth (BHIB, 
Difco) on to sheep blood $5 \% \mathrm{v} / \mathrm{v}$ agar. After incubation for $24 \mathrm{~h}$ at $37^{\circ} \mathrm{C}$, the blood agar plates were examined for haemolysis around the colonies.

\section{Preparation of culture filtrates for haemolysin production}

Culture filtrates (CFs) of $V$. cholerae non-O1 strains shown to be haemolytic were prepared by the method of Richardson et al. [21]. Briefly, $10 \mathrm{ml}$ of BHIB contained in a $50-\mathrm{ml}$ conical flask were inoculated with five or six colonies from an overnight culture on blood agar plates. The flasks were incubated at $37^{\circ} \mathrm{C}$ in a shaking water bath for $16-18 \mathrm{~h}$ with $80-120$ oscillations $/ \mathrm{min}$. The cultures were centrifuged at $22000 \mathrm{~g}$ for $20 \mathrm{~min}$ at $4^{\circ} \mathrm{C}$, supernates were filtered through a membrane filter (Millipore, $0.22 \mu \mathrm{m}$ ) and stored at $4^{\circ} \mathrm{C}$. These CFs were used for haemolysin assay.

\section{Preparation of culture filtrates for enterotoxin production}

CFs of $V$. cholerae non-O1 strains that gave positive ileal loop reactions were prepared in AKI medium by the method described above. The AKI medium (Bactopeptone $1.5 \% \mathrm{w} / \mathrm{v}$, yeast extract $0.4 \%, \mathrm{NaCl} 0.5 \%$ and $\mathrm{NaHCO}_{3} 0.3 \%$ ) was prepared as described by Iwanaga et al. [22]. The sodium bicarbonate was filter sterilised separately and mixed with the other autoclaved ingredients. Freshly prepared medium was always used; the $\mathrm{pH}$ of this medium was $c .7 .4$ without adjustment.

\section{Titration of haemolysin}

The production of haemolysin by each strain of $V$. cholerae non-O1 was confirmed by the method of Smith [23] as modified by Rennie and Arbuthnott [24] and as described by Singh and Sanyal [25]. Briefly, sheep erythrocytes (SRBC) were washed three times in isotonic saline and a $2 \%$ suspension was prepared in $0.04 \mathrm{M}$ phosphate-buffered saline (PBS, pH 7.4). Haemolytic activity was determined by mixing $0.5 \mathrm{ml}$ of two-fold serial dilutions of $\mathrm{CF}$ of each strain with an equal volume of SRBC $2 \%$ suspension. After incubation at $37^{\circ} \mathrm{C}$ in a water-bath for $2 \mathrm{~h}$ and standing at $4^{\circ} \mathrm{C}$ for $12 \mathrm{~h}$, the lysed portion was diluted four-fold with sterile normal saline and the optical density was measured in a colorimeter. Standardisation of erythrocyte suspension was by lysis of $0.5 \mathrm{ml}$ of SRBC $2 \%$ with a few crystals of saponin. An optical density of 0.5 at $540 \mathrm{~nm}$ was considered to indicate a standardised SRBC $2 \%$. The negative control was $0.5 \mathrm{ml}$ of saline instead of $\mathrm{CF}$. One haemolytic unit (HU) was defined as the amount of CF that caused $50 \%$ haemolysis under experimental conditions.

\section{Ileal loop test}

Live cells and CFs of all the strains of $V$. cholerae non$\mathrm{O} 1$ were tested for enterotoxin production in adult albino rabbits by the method of De and Chatterjee [26]. Briefly, bacteria grown in peptone water for $3 \mathrm{~h}$ were diluted 10-fold in the same medium and $1 \mathrm{ml}$ (containing $10^{5}-10^{6} \mathrm{cfu}$ ) was inoculated into the RIL. A peptone water culture of toxigenic strain $569 \mathrm{~B}$ of $V$. cholerae and unseeded peptone water served as positive and negative controls, respectively. CFs ( $1 \mathrm{ml}$, prepared in AKI medium) were also tested in the same way. Each test was done in two rabbits. Rabbits were killed after $8 \mathrm{~h}$.

\section{Passage through RIL}

Strains of $V$. cholerae non-O1 that caused little or no fluid accumulation in the initial tests were passaged through RILs according to the method of Sanyal et al. $[27,28]$. Briefly, each strain was cultured aseptically from RIL on nutrient agar and incubated overnight; five or six colonies were inoculated into peptone water and incubated for $3 \mathrm{~h}$; and $1 \mathrm{ml}$ of diluted culture was inoculated again into a RIL. The process was continued until a positive response was obtained.

\section{Results}

Twenty-four of the 28 isolates of $V$. cholerae non-O1 tested produced haemolysis on sheep blood 5\% agar plates (Table 1). CFs of these isolates also caused lysis of sheep erythrocytes in $2 \%$ suspension. The remaining

Table 1. Haemolytic activity of $V$. cholerae non-O1 strains before and after passage through RILs*

\begin{tabular}{|c|c|c|c|c|}
\hline \multirow[b]{2}{*}{$\begin{array}{l}\text { Source and } \\
\text { haemolytic } \\
\text { character }\end{array}$} & \multicolumn{2}{|c|}{ Before passage } & \multicolumn{2}{|c|}{ After passage } \\
\hline & $\begin{array}{c}\text { Number } \\
\text { tested }\end{array}$ & $\begin{array}{l}\text { Haemolysin } \\
\text { production } \\
(\mathrm{HU} / \mathrm{ml})\end{array}$ & $\begin{array}{c}\text { Number } \\
\text { tested }\end{array}$ & $\begin{array}{c}\text { Haemolysin } \\
\text { production } \\
(\mathrm{HU} / \mathrm{ml})\end{array}$ \\
\hline \multicolumn{5}{|l|}{ Diarrhoeal } \\
\hline Haemolytic & 8 & $8-64$ & 0 & \\
\hline Non-haemolytic & 2 & ND & 2 & $8-16$ \\
\hline \multicolumn{5}{|l|}{ Environmental } \\
\hline Haemolytic & 16 & $8-64$ & 0 & $\ldots$ \\
\hline Non-haemolytic & 2 & ND & 2 & $8-32$ \\
\hline
\end{tabular}

ND, not detected.

*Non-haemolytic strains tested only after animal passage. 
four isolates became haemolytic after one-to-three consecutive passages through RILs. The titres of haemolytic activity were 4-64 HU/ml. No difference in the titres of haemolytic activity was observed in relation to the source of the strains. However, there was strain-to-strain variation in the titres of haemolysin produced (Table 1).

In the initial tests with $V$. cholerae non-O1 in RILs, live cells of eight of the 28 isolates caused fluid accumulation; six of them were haemolytic and two were non-haemolytic. The remaining haemolytic strains did not cause any fluid outpouring. CFs of the RIL-positive strains caused a similar secretory response. With organisms from both sources, there were strain variations in the volume of fluid accumulation, and also variation between individual loops inoculated with the same strain (Table 2).

Environmental $V$. cholerae non-O1 strains caused significantly (Students $t$ test, $\mathrm{p}<0.05$ ) more fluid accumulation than the diarrhoeal isolates regardless of their haemolytic character (Fig. 1).

After one-to-three consecutive passages through RILs, $18(75 \%)$ of the 24 haemolytic and two $(50 \%)$ of the four non-haemolytic $V$. cholerae strains that caused little or no accumulation of fluid in the initial experiments did so (Table 2).

Two non-haemolytic and 13 haemolytic strains of $V$. cholerae non-O1 tested by consecutive passages in RILs, caused marked increase in fluid accumulation after each passage (Table 3). The titres of haemolysin produced also increased after each passage. However, on repeated subcultures or on storage in the laboratory, all these strains reverted to their original haemolytic but non-toxigenic character. The three nontoxigenic isolates of environmental origin that caused no fluid accumulation even after four consecutive passages through RILs, showed lysis of sheep erythrocytes $2 \%$ suspension (Table 3 ).

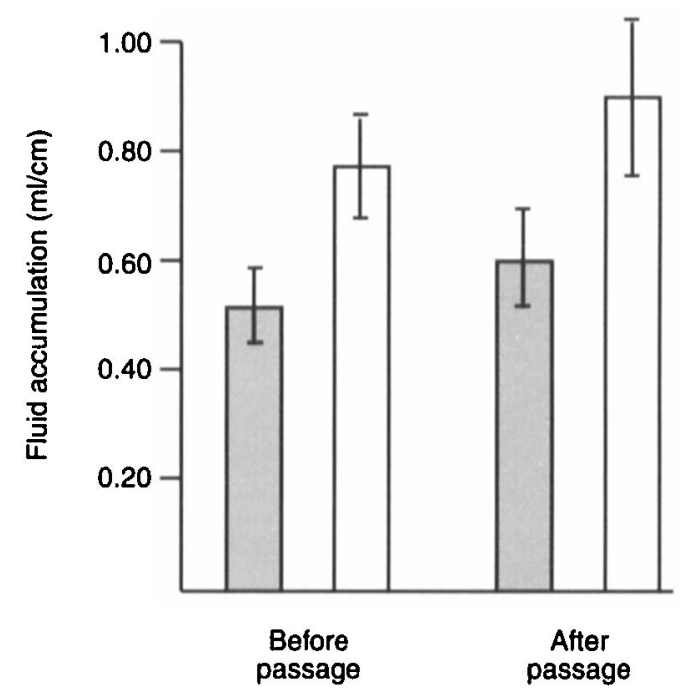

Fig. 1. Enterotoxicity of diarrhoeal (ख) and environmental $(\square)$ isolates of $V$. cholerae non-O1 strains before and after passage through RILs. The bars on the columns indicate the range of fluid accumulation caused by different strains.

\section{Discussion}

The majority of strains of $V$. cholerae non-O1 showed haemolysis on sheep blood $5 \%$ agar plates in the initial tests. However, a few of the non-haemolytic strains became haemolytic after one-to-three consecutive passages through RILs. Moreover, the titres of haemolysin in CFs also increased after consecutive passages. This phenomenon may be explained by the genetic evidence that the sequences homologous to $\mathrm{El}$ Tor haemolysin gene are present in both haemolytic and non-haemolytic strains of $V$. cholerae non-O1 but are probably not expressed in non-haemolytic isolates $[29,30]$.

Several workers suggested that El Tor-like haemolysin produced by $V$. cholerae non-O1 strains may be responsible for their enterotoxic activity [15-17].

Table 2. Haemolytic activity and enterotoxicity of $V$. cholerae non-O1 strains

\begin{tabular}{|c|c|c|c|c|c|}
\hline \multirow[b]{2}{*}{$\begin{array}{l}\text { Source and } \\
\text { haemolytic } \\
\text { character }\end{array}$} & \multirow[b]{2}{*}{$\begin{array}{l}\text { Number of } \\
\text { strains } \\
\text { tested }\end{array}$} & \multicolumn{2}{|c|}{ Before passage } & \multicolumn{2}{|c|}{ After passage* } \\
\hline & & $\begin{array}{c}\text { Number showing } \\
\text { fluid } \\
\text { accumulation }\end{array}$ & $\begin{array}{c}\text { Fluid } \\
\text { accumulation } \\
(\mathrm{ml} / \mathrm{cm} \text { of } \mathrm{RIL})\end{array}$ & $\begin{array}{c}\text { Number showing } \\
\text { fluid } \\
\text { accumulation }\end{array}$ & $\begin{array}{c}\text { Fluid } \\
\text { accumulation } \\
(\mathrm{ml} / \mathrm{cm} \text { of } \mathrm{RIL})\end{array}$ \\
\hline \multicolumn{6}{|l|}{ Diarrhoeal } \\
\hline Haemolytic & 8 & 2 & $0.46-0.6$ & 6 & $0.42-0.8$ \\
\hline Non-haemolytic & 2 & 1 & $0.44-0.6$ & 1 & ND \\
\hline \multicolumn{6}{|l|}{ Environmental } \\
\hline Haemolytic & 16 & 4 & $0.60-1.0$ & 9 & $0.66-1.2$ \\
\hline Non-haemolytic & 2 & 1 & $0.60-0.8$ & 1 & ND \\
\hline Positive control ${ }^{\dagger}$ & 1 & 1 & $0.90-1.2$ & & $1.0-1.4$ \\
\hline Negative control ${ }^{\ddagger}$ & 0 & 0 & 0 & & 0 \\
\hline
\end{tabular}

ND, not determined.

${ }^{*}$ These strains were tested only after animal passage.

${ }^{\dagger}$ Peptone water culture of $V$. cholerae $569 \mathrm{~B}$ inoculated into RIL of each animal.

${ }^{\ddagger}$ Peptone water. 
Table 3. Influence of RIL passage on haemolytic character, fluid accumulation and haemolysis titre of $V$. cholerae non-O1 strains

\begin{tabular}{|c|c|c|c|c|c|c|c|c|c|c|c|}
\hline \multirow{3}{*}{$\begin{array}{l}\text { Strain } \\
\text { no. }\end{array}$} & \multirow{3}{*}{$\begin{array}{l}\text { Haemolytic } \\
\text { character }\end{array}$} & \multicolumn{10}{|c|}{ Fluid accumulation $(\mathrm{ml} / \mathrm{cm})$ and haemolysis titre $(\mathrm{HU} / \mathrm{ml})$ after passage no. } \\
\hline & & \multicolumn{2}{|c|}{0} & \multicolumn{2}{|c|}{1} & \multicolumn{2}{|c|}{2} & \multicolumn{2}{|c|}{3} & \multicolumn{2}{|c|}{4} \\
\hline & & $\mathrm{ml} / \mathrm{cm}$ & $\mathrm{HU} / \mathrm{ml}$ & $\mathrm{ml} / \mathrm{cm}$ & $\mathrm{HU} / \mathrm{ml}$ & $\mathrm{ml} / \mathrm{cm}$ & $\mathrm{HU} / \mathrm{ml}$ & $\mathrm{ml} / \mathrm{cm}$ & $\mathrm{HU} / \mathrm{ml}$ & $\mathrm{ml} / \mathrm{cm}$ & $\mathrm{HU} / \mathrm{ml}$ \\
\hline D-12 & Haemolytic & $*$ ND & 64 & 0.46 & † 64 & 0.60 & NT & NT & NT & NT & NT \\
\hline D-13 & Haemolytic & *ND & 8 & 0.60 & ${ }^{\dagger} 16$ & 0.72 & NT & NT & NT & NT & NT \\
\hline D-12475 B & Haemolytic & ${ }^{*} \mathrm{ND}$ & 32 & ND & 32 & 0.58 & ${ }^{\dagger} 64$ & NT & NT & NT & NT \\
\hline D-13094 RAN & Haemolytic & $* 0.7$ & $\dagger 16$ & 0.86 & 64 & NT & NT & NT & NT & NT & NT \\
\hline D-12158 RAN & Non-haemolytic & 0.44 & ${ }^{\dagger} \mathrm{ND}$ & ${ }^{*} 0.68$ & 8 & 0.76 & 32 & NT & NT & NT & NT \\
\hline E-RP-86 & Haemolytic & *ND & 8 & ND & 16 & 0.80 & ${ }^{\dagger} 64$ & 0.90 & NT & NT & NT \\
\hline E-DSM-86 & Haemolytic & ${ }^{*} 0.8$ & ${ }^{\dagger} 64$ & 1.0 & 128 & 1.2 & 256 & 1.4 & NT & NT & NT \\
\hline E-AS-88 & Haemolytic & ${ }^{*} \mathrm{ND}$ & 64 & ND & 64 & ND & 128 & 0.68 & $\dagger 256$ & NT & NT \\
\hline E-SH-88 & Haemolytic & ${ }^{*} \mathrm{ND}$ & 32 & 0.66 & ${ }^{\dagger} 64$ & 0.90 & 128 & 1.1 & 128 & NT & NT \\
\hline E-TG2-86 & Haemolytic & ${ }^{*} \mathrm{ND}$ & 16 & ND & 32 & ND & 32 & 0.70 & ${ }^{\dagger} 64$ & 0.90 & NT \\
\hline E-HG-86 & Haemolytic & ${ }^{*} \mathrm{ND}$ & 64 & ND & 64 & ND & 128 & 0.70 & $\dagger 256$ & 0.9 & NT \\
\hline E-CH-86 & Haemolytic & ${ }^{*} \mathrm{ND}$ & 32 & ND & 64 & ND & NT & ND & NT & ND & NT \\
\hline E-HGS-86 & Haemolytic & $* \mathrm{ND}$ & 8 & ND & 16 & ND & 32 & ND & NT & ND & NT \\
\hline E-SHS-86 & Haemolytic & ${ }^{*} \mathrm{ND}$ & 16 & ND & 32 & ND & 32 & ND & 64 & ND & NT \\
\hline E-TG1-86 & Non-haemolytic & ND & ND & ${ }^{*} \mathrm{ND}$ & 16 & 0.50 & $\$ 32$ & 0.66 & 64 & NT & NT \\
\hline
\end{tabular}

ND, not detected; NT, not tested; D, diarrhoeal; E, environmental.

${ }^{*}$ Change to haemolysis detected; $†$ enterotoxin produced.

However, the observation that more than two-thirds of the haemolytic strains were unable to produce a secretory response in the initial tests indicates that haemolysin may not be responsible for enterotoxic activity. This observation is further strengthened by the fact that three haemolytic strains did not cause accumulation of fluid even after four consecutive passages, although they showed enhanced haemolytic activity. Moreover, the observation that $50 \%$ of the non-haemolytic strains showed enterotoxic activity also supports this conclusion. All these data suggest that the secretory response without any blood and mucous observed in RILs is most probably due to the enterotoxin(s) produced by the organism.

The environmental strains of $V$. cholerae non-O1 caused significantly more fluid accumulation than the diarrhoeal isolates. A probable explanation of this difference in the degree of enterotoxicity may be the observation, made in this laboratory that, that compared to diarrhoeal isolates, strains of environmental origin produced quantitatively more constitutive chitinase. Some strains even elaborated inducible chitinase and both these properties correlated with greater enterotoxicity (unpublished data). Similar observations were also made in relation to Aeromonas spp. of clinical and environmental origin [31].

The strains of $V$. cholerae non-O1 that failed to produce enterotoxin in the initial tests caused fluid accumulation after one-to-three consecutive passages through RILs, suggesting that almost all the strains of $V$. cholerae non-O1 were potentially enterotoxigenic. Similar observations on the effect of passage through the gut of a susceptible host were made in earlier studies with $V$. cholerae non-O1 [2,32] and also with many other organisms, such as $V$. cholerae O1 [27, 28], $V$. fluvialis [33], $V$. mimicus [27, 34], Aeromonas spp. [35-38], Plesiomonas shigelloides [39] and Klebsiella pneumoniae [40]. Furthermore, it is also known that the so-called hypertoxigenic strain 569B of $V$. cholerae $\mathrm{Ol}$ also requires passage through the rabbit gut for enhancement of toxin production. A mechanism of repression and derepression of the toxin gene may account for this phenomenon. It is possible that the toxigenicity of the fresh isolates in this study might have decreased during one-to-three subcultures in vitro before the ileal loop tests. It appears that expression of toxin genes in a bacterial strain is a means of adaptation to a particular micro-environment as occurs in $V$. cholerae [41].

The observation that the majority of strains were nontoxigenic but haemolytic in the initial tests indicates that there is no correlation between these two properties. Furthermore, the three haemolytic strains of $V$. cholerae non-O1 that failed to cause accumulation of fluid after four consecutive passages through RILs also confirms this conclusion.

The present study indicates that strains of $V$. cholerae non-O1, irrespective of their haemolytic character and sources, are potentially enterotoxigenic and that enterotoxin, not haemolysin, is the factor most likely to be responsible for their enterotoxic activity. Passage through the gut of a susceptible host may control the expression of the gene responsible for haemolysin and enterotoxin production.

The study was supported in part by the Council of Scientific and Industrial Research, New Delhi as a fellowship to D.V.S. The authors are grateful to Mr D. Venu Gopal for secretarial assistance and Ms Anjali Tikoo for technical assistance during the study. 


\section{References}

1. Blake PA, Weaver RW, Hollis DG. Diseases of human's (other than cholera) caused by vibrios. Annu Rev Microbiol 1980; 34: 341-367.

2. Sanyal SC. NAG Vibrio toxin. In: Dorner F, Drews J (eds) Pharmacology of bacterial toxins. International encyclopedia of pharmacology and therapeutics, 119. Oxford, Pergamon Press. 1986: 207-225.

3. Gelbart SM, Prabhudesai MM. Vibrio cholerae non-O1 cellulitis. Arch Pathol Lab Med 1986; 110: 1182-1183.

4. Hughes JM, Hollis DG, Gangarosa EJ, Weaver RE. Noncholera Vibrio infections in the United States. Clinical, epidemiologic, and laboratory features. Ann Intern Med 1978; 88: 602-606.

5. Safrin S, Morris JG, Adams M, Pons V, Jacob R, Conte JE. Non-O:I Vibrio cholerae bacteremia: a case report and review. Rev Infect Dis 1988; 10: 1012-1017.

6. Lahiri A, Agarwal RK, Sanyal SC. Biological similarity of enterotoxins of Vibrio cholerae serotypes other than type 1 to cholera toxin and Escherichia coli heat-labile enterotoxin. $J$ Med Microbiol 1982; 15: 429-440.

7. Singh DV, Tikoo A, Sanyal SC. Production of the new cholera toxin by environmental isolates by Vibrio cholerae non-O1 I Med Microbiol 1996; 45: 31-34.

8. Arita M, Takeda T, Honda T, Miwatani T. Purification and characterization of Vibrio cholerae non-O1 heat-stable enterotoxin. Infect Immun 1986; 52: 45-49.

9. Honda T, Arita M, Takeda T, Yoh M, Miwatani T. Non-O1 Vibrio cholerae produces two newly identified toxins related to Vibrio parahaemolyticus haemolysin and Escherichia coli heatstable enterotoxin. Lancet 1985; 2: 163-164.

10. Takao T, Shimonishi Y, Kobayashi $\mathrm{M}$ et al. Amino acid sequence of heat-stable enterotoxin produced by Vibrio cholerae non-O1. FEBS Lett 1985; 193: 250-254

11. Yoshimura S, Takao T, Shimonishi Y et al. A heat-stable enterotoxin of Vibrio cholerae non-O1: chemical synthesis, and biological physicochemical properties. Biopolymers 1986; 25 Suppl: S69-S83.

12. Yoh M, Honda T, Miwatani T. Production by non-Ol Vibrio cholerae of haemolysin related to thermostable direct haemolysin of Vibrio parahaemolyticus. FEMS Microbiol Lett 1985; 29: $197-200$

13. O'Brien AD, Chen ME, Holmes RK, Kaper J, Levine MM. Environmental and human isolates of Vibrio cholerae and Vibrio parahaemolyticus produce a shigella dysenteriae 1 (shiga)-like cytotoxin. Lancet 1984; 1: 77-78.

14. Hanne LF, Finkelstein RA. Characterization and distribution of the hemagglutinins produced by Vibrio cholerae. Infect Immun 1982; 36: 209-214.

15. Yamamoto K, Al-Omani M, Honda T, Takeda Y, Miwatani T Non-Ol Vibrio cholerae hemolysin: purification, partial characterization, and immunological relatedness to El Tor hemolysin. Infect Immun 1984; 45: 192-196.

16. Yamamoto $\mathrm{K}$, Ichinose $\mathrm{Y}$, Nakasone $\mathrm{N}$ et al. Identity of hemolysins produced by Vibrio cholerae, non-Ol $V$. cholerae $\mathrm{Ol}$, biotype El Tor. Infect Immun 1986; 51: 927-931.

17. Ichinose $\mathrm{Y}$, Yamamoto $\mathrm{K}$, Nakasone $\mathrm{N}$ et al. Enterotoxicity of El Tor-like hemolysin of non-O1 Vibrio cholerae. Infect Immun 1987; 55: 1090-1093.

18. Alm RA, Stroeher UH, Manning PA. Extracellular proteins of Vibrio cholerae: nucleotide sequence of the structural gene (hlyA) for the haemolysin of the haemolytic El Tor strain of 017 and characterization of the hlyA mutation in the nonhaemolytic classical strain 569B. Mol Microbiol 1988; 2: 481488.

19. Tikoo A, Singh DV, Sanyal SC. Influence of animal passage on haemolysin and enterotoxin production in Vibrio cholerae $\mathrm{O} 1$ biotype El Tor strains. J Med Microbiol 1994; 40: 246-251.
20. World Health Organization. Programme for control of diarrhoeal diseases (CDD/83.3 Rev. 1). In: Manual for laboratory investigations of acute enteric infections. Geneva, World Health Organization. 1987.

21. Richardson K, Michalski J, Kaper JB. Hemolysin production and cloning of two hemolysin determinants from classical Vibrio cholerae. Infect Immun 1986; 54: 415-420.

22. Iwanaga $M$, Yamamoto $K$, Higa $N$, Ichinose $Y$, Nakasone $N$, Tanabe M. Culture conditions for stimulating cholera toxin production by Vibrio cholerae O1 El Tor. Microbiol Immunol 1986; 30: 1075-1083.

23. Smith HW. Haemolysins of Escherichia coli. J Pathol Bacteriol 1963; 85: 197-211.

24. Rennie RP, Arbuthnott JP. Partial characterisation of Escherichia coli haemolysin. J Med Microbiol 1974; 7: 179-188.

25. Singh DV, Sanyal SC. Production of haemolysis and its correlation with enterotoxicity in Aeromonas spp. $J$ Med Microbiol 1992; 37: 262-267.

26. De SN, Chatterje DN. Experimental study of the mechanism of action of Vibrio cholerae on the intestinal mucous membrane. $J$ Pathol Bacteriol 1953; 66: 559-562.

27. Sanyal SC, Huq MI, Neogy PKB, Alam K, Kabir MI, Rahaman ASMH. Experimental studies on the pathogenicity of Vibrio mimicus strains isolated in Bangladesh. Aust J Exp Bio Med Sci 1984; 62: 515-521.

28. Sanyal SC, Neogy PKB, Alam K, Huq MI, Al-Mahmud KA. A new enterotoxin produced by Vibrio cholerae O1. J Diarrhoeal Dis Res 1984; 2: 3-12.

29. Brown MH, Manning PA. Haemolysin gene of Vibrio cholerae: presence of homologous DNA in non-haemolytic $\mathrm{OI}$ and haemolytic non O1 strains. FEMS Microbiol Lett 1985; 30: 197-201.

30. Yamamoto $\mathrm{K}$, Ichinose $\mathrm{Y}$, Shinagawa $\mathrm{H}$ et al. Two-step processing for activation of the cytolysin/hemolysin of Vibrio cholerae $\mathrm{O} 1$ biotype $\mathrm{El}$ Tor: nucleotide sequence of the structural gene (hlyA) and characterization of the processed products. Infect Immun 1990; 58: 4106-4116.

31. Singh DV, Sanyal SC. Production of chitinase by enterotoxigenic Aeromonas species isolated from clinical and environmental sources. J Diarrhoeal Dis Res 1992; 10: 213-216.

32. Shankar P, Agarwal RK, Sanyal SC. Experimental studies on enteropathogenicity of Vibrio cholerae serotypes other than O1. Zentralbl Bakteriol Mikrobiol Hyg A 1982; 252: $514-524$.

33. Sanyal SC, Agarwal RK, Annapurna E, Lee JV. Enterotoxicity of group F vibrios. Jpn J Med Sci Biol 1980; 33: 217-222.

34. Sanyal SC, Huq MI, Neogy PKB et al. Vibrio mimicus as an aeteologic agent of diarrhoea and its pathogenesis. Indian $J$ Med Microbiol 1983; 1: 1-12.

35. Annapurna E, Sanyal SC. Studies on enteropathogenicity of Aeromonas hydrophila in an experimental model. Indian $J$ Prev Soc Med 1975; 6: 234-237.

36. Annapurna E, Sanyal SC. Enterotoxicity of Aeromonas hydrophila. J Med Microbiol 1977; 10: 317-323.

37. Singh DV, Sanyal SC. Haemolysin and enterotoxin production by Aeromonas caviae isolated from diarrhoeal patients, fish and environment. $J$ Diarrhoeal Dis Res 1992; 10: 16-20.

38. Singh DV, Sanyal SC. Enterotoxicity of clinical and environmental isolates of Aeromonas spp. J Med Microbiol 1992; 36: 269-272.

39. Sanyal SC, Saraswathi B, Sharma P. Enteropathogenicity of Plesiomonas shigelloides. J Med Microbiol 1980; 13: 401-409.

40. Raychaudhury A, Agarwal RK, Sanyal SC. Enteropathogenicity of Klebsiella pneumoniae strains isolated from stools of diarrhoeal patients and other clinical specimens: an experimental study. Zentralbl Bakteriol Mikrobiol Hyg A 1984; 258 94-103.

41. Singh SJ, Sanyal SC. Enterotoxicity of so-called NAG vibrios. Ann Soc Belg Med Trop 1978; 58: 133-140. 